TITLE:

\title{
Iron oxide catalyzed reduction of acid chlorides to aldehydes with hydrosilanes
}

$\operatorname{AUTHOR}(\mathrm{S}):$

Cong, Cong; Fujihara, Tetsuaki; Terao, Jun; Tsuji, Yasushi

CITATION:

Cong, Cong ... [et al]. Iron oxide catalyzed reduction of acid chlorides to aldehydes with hydrosilanes. Catalysis Communications 2014, 50: 25-28

ISSUE DATE:

2014-05-05

URL:

http://hdl.handle.net/2433/187076

RIGHT:

C 2014 Elsevier B.V.; この論文は出版社版でありません。引用の際には 出版社版をご確認ご利用ください。; This is not the published version. Please cite only the published version. 


\title{
Iron Oxide Catalyzed Reduction of Acid Chlorides to Aldehydes with Hydrosilanes
}

\section{Cong Cong, Tetsuaki Fujihara, Jun Terao, and Yasushi Tsuji*}

Department of Energy and Hydrocarbon Chemistry, Graduate School of Engineering, Kyoto University, Kyoto 615-8510, Japan.

TEL: +81-75-383-2515,FAX: +81-75-383-2514.E-mail: ytsuji@scl.kyoto-u.ac.jp

\begin{abstract}
Iron-catalyzed reduction of acid chlorides to the corresponding aldehydes with a hydrosilane as a reducing agent has been developed. A simple mixture of a commercially available iron oxide $(\mathrm{FeO})$ and tris(2,4,6-trimethoxyphenyl)phosphine (TMPP) as a catalyst realized the reduction of acid chlorides to the corresponding aldehydes under mild reaction conditions.
\end{abstract}

Keywords:

Acid chlorides, Aldehydes, Hydrosilanes, Iron oxide, Reduction 


\section{Introduction}

Acid chlorides are utilized as promising substrates in various organic reactions with transition-metal catalysts [1-5] because the oxidative addition of (acyl) carbon-chlorine bond to a low-valent metal center smoothly occurs [6]. Recently, we have reported iridium-catalyzed addition reaction of acid chlorides to terminal alkynes [7, 8]. Importantly, aliphatic acid chlorides as well as aroyl chlorides could be used in the addition reaction with suppression of decarbonylation and $\beta$-hydrogen elimination which have been two major intrinsic problems in transition-metal-catalyzed reactions [8]. We also found the palladium-catalyzed reactions of acid chlorides with hydrosilanes in the presence of allenes, giving $\alpha, \beta$-unsaturated ketones regio- and stereoselectively [9].

The reduction of acid chlorides to aldehydes is one of important methods to afford aldehydes. The transformation with molecular hydrogen over supported heterogeneous palladium catalysts $\left(\mathrm{Pd} / \mathrm{BaSO}_{4}\right)$ is well-known as the Rosenmund reduction [10]. However, in the reaction, the uptake of hydrogen must be monitored to avoid the over reduction. Homogeneous transition-metal catalyzed reductions of acid chlorides to the corresponding aldehydes have been also developed employing palladium [11] or ruthenium [12] as catalysts. Recently, we have reported a very efficient method of aldehydes synthesis from acid chlorides employing palladium catalysis and hydrosilane, which is stable, easy-to-handle and efficient reducing reagents [13]. Furthermore, we also developed the palladium-catalyzed reduction of carboxylic acids to the corresponding aldehydes in the presence of pivalic anhydride and hydrosilane [14]. Although these were good catalytic reactions, complexes of precious metals such as ruthenium and palladium must be used.

Recently, much attention has been paid to iron catalysts since iron is one of the most abundant metals on the earth. Efficient iron-catalyzed transformations including carbon-carbon bond forming reactions has been developed to date [15-19]. Regarding iron-catalyzed reductive transformations [20-31], iron complexes were found to be active for reductions of carbonyl compounds such as aldehydes [20, 21], ketones [20, 21], and amides [22]. However, some iron complexes must be prepared before use and they might be unstable for further handling [20, 21]. Therefore, iron-catalyzed transformation by the use of simple and commercially available catalyst precursors or in situ generated system is highly desired.

In the present study, we report that acid chlorides can be reduced to the corresponding aldehydes employing hydrosilane as a reducing agent in the presence of a catalytic amount of iron oxide ( $\mathrm{FeO}$ ) (99.9\% purity). Iron oxides such as $\mathrm{FeO}$ or $\mathrm{Fe}_{2} \mathrm{O}_{3}$ are known as catalysts in dehydrogenation reaction [32], Fenton reaction [33], or Fisher-Tropsch reaction [34]. However, 
to the best of our knowledge, there has been no precedent for the iron-catalyzed reduction of acid chlorides to aldehydes.

\section{Experimental}

\subsection{General procedure}

All manipulations were performed under an argon atmosphere using standard Schlenk-type glassware on a dual-manifold Schlenk line. Unless otherwise noted, materials obtained from commercial suppliers were used without further purification. THF and toluene were dried and purified before use by usual methods [35]. ${ }^{1} \mathrm{H}$ NMR spectra were measured with a JEOL ECX-400P spectrometer. The ${ }^{1} \mathrm{H}$ NMR chemical shifts are reported relative to tetramethylsilane (TMS, $0.00 \mathrm{ppm}$ ). The ${ }^{13} \mathrm{C}$ NMR chemical shifts are reported relative to $\mathrm{CDCl}_{3}(77.0 \mathrm{ppm})$. GC analysis was carried out using Shimadzu GC-17A equipped with an integrator $(\mathrm{C}-\mathrm{R} 8 \mathrm{~A})$ with a capillary column $(\mathrm{CBP}-1,0.25 \mathrm{~mm}$ i.d. $\times 25 \mathrm{~m})$. Matrix-assisted laser desorption/ionization time-of-flight (MALDI-TOF) mass spectra were acquired on a SHIMADZU AXIMA-CFR Plus or a Bruker Autoflex using $\alpha$-cyano-4-hydroxycinnamic acid as a matrix and NaTFA as a cationization reagent. Medium-pressure column chromatography was performed with a Biotage IsoleraOne. Column chromatography was carried out on silica gel (Kanto N60, spherical, neutral, 63-210 $\mu \mathrm{m}$ ). TLC analyses were performed on commercial glass plates bearing a 0.25 -mm layer of Merck Silica gel 60F254. Iron oxide (FeO, 99.9\% purity) was purchased from Aldrich and used without further purification.

\subsection{Catalytic reaction}

A typical procedure for the iron oxide catalyzed reduction of 3-phenylpropionyl chloride (1a) with $\mathrm{H}_{3} \mathrm{SiPh}$ (Table 1, entry 1): iron oxide (3.6 mg, $\left.0.050 \mathrm{mmol}\right)$ and TMPP (6.7 mg, 0.013 mmol) were added to a $10 \mathrm{~mL}$ Schlenk flask with a magnetic stir bar. The flask was evacuated and backfilled with argon three times. Then, $\mathrm{H}_{3} \mathrm{SiPh}(34 \mu \mathrm{L}, 0.28 \mathrm{mmol})$ was added to the flask and the reaction mixture was stirred at $60{ }^{\circ} \mathrm{C}$ for $20 \mathrm{~h}$ under an argon atmosphere. Then, toluene $(0.50 \mathrm{~mL})$ was added to the flask and the resultant solution was stirred at room temperature for $5 \mathrm{~min}$ before $1 \mathrm{a}(37 \mu \mathrm{L}, 0.25 \mathrm{mmol})$ was loaded. Further, the reaction mixture was stirred at $60{ }^{\circ} \mathrm{C}$ for $20 \mathrm{~h}$ under an argon atmosphere. After cooling to room temperature, the reaction mixture was diluted with diethyl ether $(5.0 \mathrm{~mL})$ and tetradecane $(50 \mu \mathrm{L}, 0.19 \mathrm{mmol})$ as an internal standard was added. The yield of 3-phenylpropanal (2a; 57\%) was analyzed by gas 
chromatography. 2a was isolated by silica gel column chromatography (hexane : EtOAc $=13$ : 1). Pale yellow oil (16.8 mg) was obtained in $50 \%$ yield.

\section{Results and Discussion}

To study activity of an iron catalyst system, we carried out reduction of 3-phenylpropionyl chloride (1a) as a model reaction. When all these materials including FeO, ligand, hydrosilane and 1a were mixed all at once, 2a was obtained only in moderate yields with poor reproducibility. Thus, a mixture of $\mathrm{FeO}$, tris(2,4,6-trimethoxyphenyl)phosphine (TMPP), and $\mathrm{H}_{3} \mathrm{SiPh}$ was stirred at $60{ }^{\circ} \mathrm{C}$ for $20 \mathrm{~h}$. Then, toluene and 1a were added, and the resulting mixture was further stirred at $60{ }^{\circ} \mathrm{C}$ for $20 \mathrm{~h}$. Under the reaction conditions, 3-phenylpropanal (2a) was obtained in $57 \%$ yield (entry 1). In the reaction mixture, 3-phenylpropionic acid was detected and its yield was determined as $32 \%$ by the GC internal standard method after derivatization to the corresponding methyl ester. This observation was in contrast to the palladium catalyzed reductions of acid chlorides [13], in which no carboxylic acids were formed. Without $\mathrm{FeO}$, the conversion of $\mathbf{1 a}$ was very low, and $\mathbf{2 a}$ was obtained in only $4 \%$ yield (entry 2). Next, various iron precursors in place of $\mathrm{FeO}$ were employed. The reaction with $\mathrm{Fe}_{2} \mathrm{O}_{3}$ also afforded 2a in $43 \%$ yield (entry 3), while other soluble iron precursors such as $\mathrm{FeCl}_{2}, \mathrm{FeF}_{2}$ and $\mathrm{Fe}(\mathrm{acac})_{2}$ were not effective (entries 4-6). Without phosphine, the yield of 2a considerably decreased (entry 7). Triphenylphosphine $\left(\mathrm{PPh}_{3}\right)$ was not efficient at all (entry 8). The reaction employing triarylphosphines with electron donating substituents afforded $\mathbf{2 a}$ in moderate yields (entries 9-11). Other bulky phosphines such as tris(2,4,6-trimethylphenyl)phosphine and tricyclohexylphosphine afforded the product in low yields (entries 12 and 13). Thus, the addition of a catalytic amount of a phosphine affects the activity considerably. As for a hydrosilane, $\mathrm{HSiMePh}_{2}, \mathrm{HSi}(\mathrm{OEt})_{3}, \mathrm{H}_{2} \mathrm{SiMePh}, \mathrm{H}_{2} \mathrm{SiPh}_{2}$, and PMHS (polymethylhydrosiloxane) were less effective than $\mathrm{H}_{3} \mathrm{SiPh}$ (entries $14-18$ vs entry 1). As a solvent, the reaction in THF under otherwise the same reaction conditions as entry 1 afforded 2a in $40 \%$ yield. Regarding catalyst loadings, we carried out the reactions in the presence of $10 \mathrm{~mol} \%, 5 \mathrm{~mol} \%$, and $1 \mathrm{~mol} \%$ of $\mathrm{FeO}$ (the ratio of $\mathrm{FeO}:$ TMPP was kept in 4 : 1), and in these reactions $\mathbf{2 a}$ was afforded in $49 \%, 19 \%$, and $21 \%$ yields, respectively. In addition, the ration between FeO and TMPP $(4: 1)$ was changed to $2: 1,1: 1$, and $1: 2$. As a result, the yield of $\mathbf{2 a}$ was reduced to $50 \%, 40 \%$, and $17 \%$ yields, respectively (Table S1, in the Supplementary data).

Various acid chlorides were reduced with $\mathrm{H}_{3} \mathrm{SiPh}$ in the presence of $\mathrm{FeO} / \mathrm{TMPP}$ catalyst system (Table 2). 3-Arylpropionyl chlorides with different substituents (4-Me, 4-OMe, 4-Cl, 
4-CF 3 , and 3-F) (1b-f) afforded the corresponding aldehydes (2b-f) in moderate yields (entries 1-5). Aliphatic acid chlorides such as $\mathbf{1 g}$ and $\mathbf{1 h}$ were also converted to the corresponding product (entries 6 and 7). Even sterically congested acyl chlorides such as 1i and $\mathbf{1} \mathbf{j}$ gave the products at higher reaction temperatures (entries 8 and 9). An acid chloride with an alkenyl moiety (1k) also afforded the corresponding aldehyde (2k) in $40 \%$ yield (entry 10). Although we examined the substrates with other functional groups such as ester, cyano, and nitro groups, the corresponding aldehydes were obtained only in trace yields. Unfortunately, aroyl chlorides (i.e., aromatic acid chlorides such as benzoyl chloride) could not be employed as substrates due to their low reactivities.

To gain some insight into catalytically active species, a reaction mixture of $\mathrm{FeO}$, TMPP and $\mathrm{H}_{3} \mathrm{SiPh}$ stirred at $60{ }^{\circ} \mathrm{C}$ for $20 \mathrm{~h}$. After adding toluene, the mixture was filtered through a $0.2 \mu \mathrm{m}$ membrane (13P, GL Science). Then, 1a was added to a resulting pale yellow filtrate and the mixture was further stirred at $60{ }^{\circ} \mathrm{C}$ (Scheme 1). As a result, 2a was obtained in $43 \%$ yield with 90\% conversion of 1a. Under the reaction conditions, carboxylic acid was detected as a side product. In addition, the separated dark brown solid was employed as the catalyst in the reaction of 1a. In the reaction, a trace of $\mathbf{2 a}$ was obtained with the low conversion of $\mathbf{1 a}(18 \%)$. The result may suggest that some soluble iron species would be responsible for the present catalytic reaction. Unfortunately, various measurements including MALDI-TOF MASS and X-ray crystallographic analysis to characterize active species were failed.

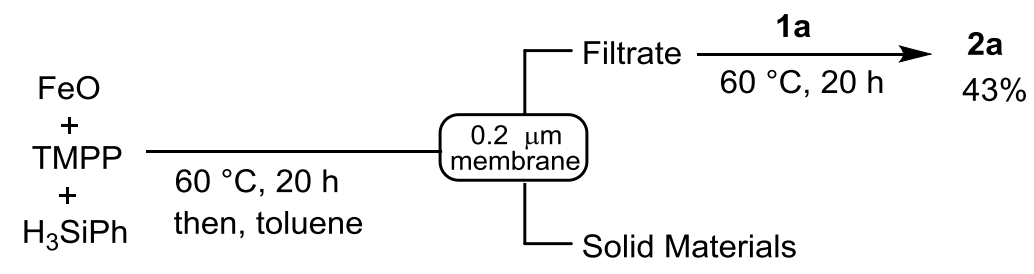

Scheme 1. Filtration test.

\section{Conclusion}

In conclusion, we found that the ion-catalyzed reduction of acid chlorides employing hydrosilane as a reducing agent. A simple mixture of a commercially available and easy-to-handle iron oxide (FeO) and 2,4,6-trimethoxyphenylphosphine (TMPP) was found to be a good catalyst. Further application to reductive transformations and elucidation of the reaction mechanisms are now in progress. 


\section{References}

[1] Y. Obora, Y. Tsuji, T. Kawamura, J. Am. Chem. Soc. 115 (1993) 10414.

[2] Y. Obora, Y. Tsuji, T. Kawamura, J. Am. Chem. Soc. 117 (1995) 9814.

[3] K. Kokubo, K. Matsumasa, M. Miura, M. Nomura, J. Org. Chem. 61 (1996) 6941.

[4] T. Sugihara, T. Satoh, M. Miura, M. Nomura, Angew. Chem. Int. Ed. 42 (2003) 4672.

[5] X. Zhao, Z. Yu, J. Am. Chem. Soc. 130 (2008) 8136.

[6] J. P. Collman, L. S. Hegedus, J. R. Norton, R. G. Finke, Principles and Applications of Organotransition Metal Chemistry; University Science Books: Mill Valley, CA, 1987; Chapter 5.

[7] T. Iwai, T. Fujihara, J. Terao, Y. Tsuji, J. Am. Chem. Soc. 131 (2009) 6668.

[8] T. Iwai, T. Fujihara, J. Terao, Y. Tsuji, J. Am. Chem. Soc. 134 (2012) 1268.

[9] T. Fujihara, K. Tatsumi, J. Terao, Y. Tsuji, Org. Lett. 13 (2013) 2286.

[10] K. W. Rosenmund, Ber. Dtsch. Chem. Ges. 51 (1918) 585.

[11] K. Lee, R. E. Maleczka Jr. Org. Lett. 8 (2006) 1887.

[12] D. V. Gutsulyak, G. I. Niknov, Adv. Synth. Catal. 354 (2012) 607

[13] T. Fujihara, C. Cong, T. Iwai, J. Terao, Y. Tsuji, Synlett. 23 (2012) 2389.

[14] T. Fujihara, C. Cong, J. Terao, Y. Tsuji, Adv. Synth. Catal. 355 (2013) 3420.

[15] W. M. Czaplik, M. Mayer, S. Grupe, A. J. von Wangelin, Pure App. Chem. 82 (2010) 1545.

[16] W. M. Czaplik, M. Mayer, J. Cvengros, A. J. von Wangelin, ChemSusChem 2 (2009) 396.

[17] B. D. Sherry, A. Fuerstner, Acc. Chem. Res. 41 (2008) 1500.

[18] A. Fuerstner, R. Martin, Chem. Lett. 34 (2005) 624.

[19] C. Bolm, J. Legros, J. L. Paih, L. Zani, Chem. Rev. 104 (2004) 6217.

[20] F. Jiang, D. Bezier, J. B. Sortais, C. Darcel, Adv. Synth. Catal. 353 (2011) 239.

[21] L. C. M. Castro, D. Bezier, J. B. Sortais, C. Darcel, Adv. Synth. Catal. 353 (2011) 1279.

[22] S. Zhou, K. Junge, D. Addis, S. Das, M. Beller, Angew. Chem. Int. Ed. 48 (2009) 9507.

[23] H. Li, L. C. M. Castro, J. Zheng, T. Roisnel, V. Dorcet, J. B. Sortais, C. Darcel, Angew. Chem. Int. Ed. 52 (2013) 8045.

[24] L. C. M. Castro, H. Li, J. B. Sortais, C. Darcel, Chem. Commun. 48 (2012) 10514.

[25] S. Grupe, A. J. von. Wangelin, ChemCatChem 5 (2013) 706.

[26] W. M. Czaplik, S. Grupe, M. Mayer, A. J. von Wangelin, Chem. Commun. 46 (2010) 6350. 
[27] H. Guo, K. Kanno, T. Takahashi, Chem. Lett. 33 (2004) 1356.

[28] F. Alonso, I. P. Beletskaya, M. Yus, Chem. Rev. 102 (2002) 4009.

[29] K. Junge, K. Schröder, M. Beller, Chem. Commun. 47 (2011) 4849.

[30] B. A. F. L. Bailly, S. P. Thomas, RSC Adv. 1 (2011) 1435.

[31] M. Zhang, A. Zhang, Appl. Organomet. Chem. 24 (2010) 751.

[32] A. Schüle, U. Nieken, O. Shekhah, W. Ranke, R. Schlögl, G. Kolios, Pys. Chem. Chem. Phys. 9 (2007) 3619.

[33] H. Lim, J. Lee, S. Jin, J. Kim, J. Yoon, T. Hyeon, Chem. Commun. (2006) 463.

[34] H. M. T. Galvis, J. H. Bitter, C. B. Khare, M. Ruitenbeek, A. I. Dugulan, K. P. de Jong, Science 335 (2012) 835.

[35] W. L. F. Armarego, C. L. L. Chai, Purification of Laboratory Chemicals, 5th ed., Burrerworth-Heinemann, Oxford, 2003. 


\section{Table 1}

Effect of iron precursors, ligands and hydrosilanes on the reduction of 3-phenylpropionyl chloride (1a). ${ }^{\text {a }}$

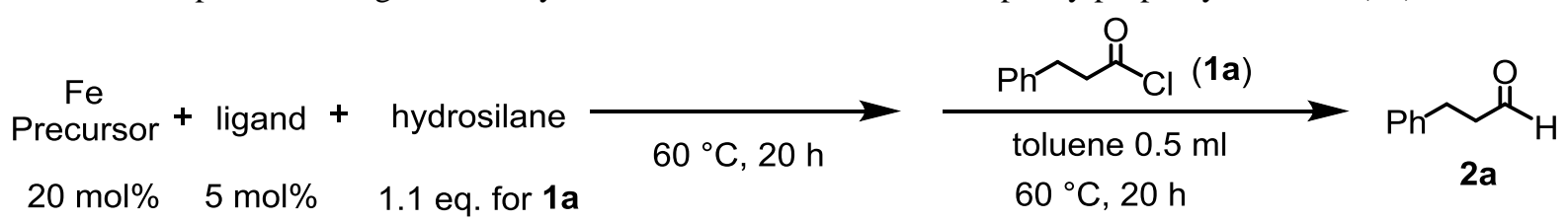

\begin{tabular}{|c|c|c|c|c|c|}
\hline Entry & Precursor & Ligand & Hydrosilane & Conv. of $1 \mathrm{a}(\%)^{\mathrm{b}}$ & Yield of $\mathbf{2 a}(\%)^{\mathrm{b}}$ \\
\hline 1 & $\mathrm{FeO}$ & TMPP & $\mathrm{H}_{3} \mathrm{SiPh}$ & 93 & $57(50)^{\mathrm{c}}$ \\
\hline 2 & none & TMPP & $\mathrm{H}_{3} \mathrm{SiPh}$ & 31 & 4 \\
\hline 3 & $\mathrm{Fe}_{2} \mathrm{O}_{3}$ & TMPP & $\mathrm{H}_{3} \mathrm{SiPh}$ & 83 & 43 \\
\hline 4 & $\mathrm{FeCl}_{2}$ & TMPP & $\mathrm{H}_{3} \mathrm{SiPh}$ & 26 & 2 \\
\hline 5 & $\mathrm{FeF}_{2}$ & TMPP & $\mathrm{H}_{3} \mathrm{SiPh}$ & 33 & 5 \\
\hline 6 & $\mathrm{Fe}(\mathrm{acac})_{2}$ & TMPP & $\mathrm{H}_{3} \mathrm{SiPh}$ & 53 & 3 \\
\hline 7 & $\mathrm{FeO}$ & none & $\mathrm{H}_{3} \mathrm{SiPh}$ & 39 & 7 \\
\hline 8 & $\mathrm{FeO}$ & $\mathrm{PPh}_{3}$ & $\mathrm{H}_{3} \mathrm{SiPh}$ & 11 & 2 \\
\hline 9 & $\mathrm{FeO}$ & $\mathrm{P}\left[2,6-(\mathrm{MeO})_{2} \mathrm{C}_{6} \mathrm{H}_{3}\right]_{3}$ & $\mathrm{H}_{3} \mathrm{SiPh}$ & 32 & 15 \\
\hline 10 & $\mathrm{FeO}$ & $\mathrm{P}\left(o-\mathrm{MeOC}_{6} \mathrm{H}_{4}\right)_{3}$ & $\mathrm{H}_{3} \mathrm{SiPh}$ & 34 & 21 \\
\hline 11 & $\mathrm{FeO}$ & $\mathrm{P}\left(p-\mathrm{MeOC}_{6} \mathrm{H}_{4}\right)_{3}$ & $\mathrm{H}_{3} \mathrm{SiPh}$ & 91 & 28 \\
\hline 12 & $\mathrm{FeO}$ & $\mathrm{P}(\mathrm{Mes})_{3}$ & $\mathrm{H}_{3} \mathrm{SiPh}$ & 13 & 1 \\
\hline 13 & $\mathrm{FeO}$ & $\mathrm{PCy}_{3}$ & $\mathrm{H}_{3} \mathrm{SiPh}$ & 62 & 33 \\
\hline 14 & $\mathrm{FeO}$ & TMPP & $\mathrm{HSiMePh}_{2}$ & 24 & 5 \\
\hline 15 & $\mathrm{FeO}$ & TMPP & $\mathrm{HSi}(\mathrm{OEt})_{3}$ & 34 & 2 \\
\hline 16 & $\mathrm{FeO}$ & TMPP & $\mathrm{H}_{2} \mathrm{SiMePh}$ & 42 & 14 \\
\hline 17 & $\mathrm{FeO}$ & TMPP & $\mathrm{H}_{2} \mathrm{SiPh}_{2}$ & 46 & 13 \\
\hline 18 & $\mathrm{FeO}$ & TMPP & PMHS & 89 & 4 \\
\hline
\end{tabular}

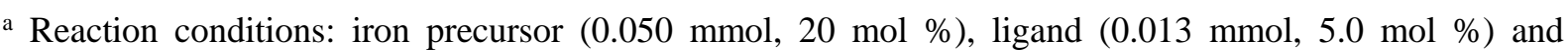
hydrosilane $(0.28 \mathrm{mmol})$ at $60{ }^{\circ} \mathrm{C}$ for $20 \mathrm{~h}$, then, $1 \mathrm{a}(0.25 \mathrm{mmol})$ and toluene $(0.50 \mathrm{~mL})$ at $60{ }^{\circ} \mathrm{C}$ for $20 \mathrm{~h}$.

${ }^{\mathrm{b}}$ Determined by GC analysis based on the internal standard technique.

${ }^{c}$ Isolated yield of $\mathbf{2 a}$. 


\section{Table 2}

Iron oxide catalyzed reduction of acid chlorides. ${ }^{\mathrm{a}}$

\begin{tabular}{|c|c|c|c|c|}
\hline Entry & Acid chlorides (1) & Teperature $\left({ }^{\circ} \mathrm{C}\right)$ & Aldehydes (2) & Yield $(\%)^{\mathrm{b}}$ \\
\hline 1 & $1 \mathrm{~b}$ & 60 & $2 b$ & $\begin{array}{c}45 \\
(64)\end{array}$ \\
\hline 2 & 1c & 60 & 2c & $\begin{array}{c}44 \\
(58)\end{array}$ \\
\hline 3 & & 60 & 2d & $\begin{array}{c}44 \\
(56)\end{array}$ \\
\hline 4 & 1e & 60 & $2 e$ & $\begin{array}{c}58 \\
(68)\end{array}$ \\
\hline 5 & 1f & 60 & $2 f$ & $\begin{array}{c}53 \\
(68)\end{array}$ \\
\hline 6 & & 60 & & $\begin{array}{c}36 \\
(40)\end{array}$ \\
\hline 7 & & 80 & $2 \mathrm{~h}$ & (47) \\
\hline 8 & $\mathbf{1 i}$ & 100 & $2 \mathbf{i}$ & (42) \\
\hline 9 & $\mathbf{l j}$ & 120 & $2 \mathbf{j}$ & (41) \\
\hline 10 & $1 \mathbf{k}$ & 60 & $2 \mathbf{k}$ & $\begin{array}{c}40 \\
(52)\end{array}$ \\
\hline
\end{tabular}

a Reaction conditions: FeO (0.050 mmol, $20 \mathrm{~mol} \%)$, TMPP (0.013 mmol, $5.0 \mathrm{~mol} \%)$ and $\mathrm{H}_{3} \mathrm{SiPh}(0.28 \mathrm{mmol})$ at $60{ }^{\circ} \mathrm{C}$ for $20 \mathrm{~h}$, then, $1(0.25 \mathrm{mmol})$ and toluene $(0.50 \mathrm{~mL})$ at $60 \sim 120^{\circ} \mathrm{C}$ for $20 \mathrm{~h}$.

b Isolated yield of 2. Value in palenthesis showed GC yield based on the internal standard technique. 